\title{
A first empirical investigation into the pleasure of control as explaining factor in usage durations of information systems
}

\author{
Michaela Kauer* and Ralph Bruder \\ Institute of Ergonomics, Technische Universität Darmstadt, Petersenstraße 30, 64287 Darmstadt, Germany
}

\begin{abstract}
To predict the technology acceptance of a system before market release is one of the big challenges of today. Many models are concerned with the question if someone is going to accept the system or not. Within this work a first empirical investigation of a personal trait called Pleasure of Control (PoC) is presented. Pleasure of Control is a construct that divides people into those people enjoy having control over a technical system and those who do not. It is predicted that a high Pleasure of Control leads to a prolonged system usage and unwillingness to accept highly automated systems. This paper presents a first empirical investigation of Pleasure of Control with 10 Persons with focus on usage durations. An experimental study revealed differences in the usage durations of a technical system (Apple iPad) between users with high and user with low Pleasure of Control measures.
\end{abstract}

Keywords: technology acceptance, usage durations, pleasure of control, automated systems

\section{Introduction}

Technical products are part of our daily life. This is true for private life as well as for work life. Regardless of the field of application some systems were originally invented to enhance consumers comfort (e.g. dishwashers or driver assistant systems). Even though these systems were in particular developed for the user, user acceptance of some of these systems is low. Some systems are not bought or rarely used. This leads to high financial loss for the releasing companies. Therefore, the question of user acceptance of new (technical) products is important and the ability to clarify this question in advance is desirable.

For the field of information systems in work places a huge number of studies were concerned with the explanation of technology acceptance during the last decades (e.g. [2], [3], [5], [7], [16]). And the explanatory power of the developed models for the working context is high [see e.g. 14]. Most studies mention the factors usability (or ease of use), usefulness and enjoyment (sometimes fun or playfulness) as important for the acceptance of a product. But as the big number of different models shows: The number of factors and the factors themselves are changing with the field of application. Considering a safety relevant area, trust and perceived safety are becoming extremely relevant [see 13]. This is also true for highly automated systems and in general, the acceptance of systems which automate actions that were formerly manually executed is often low.

Most theories in the area of highly automated systems sooner or later reach a point when perceived control over a technical system becomes relevant for the acceptance of these systems. Especially a loss of perceived control is associated with low acceptance. To prevent users from this loss of control, the construct of controllability was developed to measure the degree to which users perceive to be in control of the interaction and today, controllability is part of the ISO 9421-110 [18] which describes the main principles of an ergonomic human system interaction.

Still, the call for high controllability does not solve all problems in the area of highly automated systems.

\footnotetext{
*Corresponding author. Phone: 00496151 167040, Fax: 00496151 163488, E-mail: kauer@iad.tu-darmstadt.de
} 
Within the research project Conduct-by-Wire - which is funded by the German Research Foundation - a semi-automated maneuver-based vehicle control is developed [17]. Within this concept drivers do interact with the system by assigning maneuvers (e.g. turn left or lane change right) to the car which in return executes the maneuvers automatically. During a number of simulator studies usability and controllability of the Conduct-by-Wire systems were rated quite high, but still almost half of the participants rated the acceptance for the Conduct-by-Wire system very low. Therefore, other reasons besides controllability have to account for the missing user acceptance. Section 2 describes the series of explorations, which lead to the idea of a concept called "Pleasure of Control" (PoC). Section 3 describes the study in which PoC was empirically investigated for the first time and in section 4 the results are critically reviewed.

\section{The concept of pleasure of control}

The concept Pleasure of Control was developed in a series of explorations which are described in the following section. The section starts with results from focus groups, proceeds with results from semistructured interviews and ends with the developed questionnaire to measure Pleasure of Control.

\subsection{Focus groups}

To identify the reasons for missing user acceptance two focus groups were conducted [8]. Within those focus groups 10 young drivers (mean age 22 years) were introduced to the concept of Conduct-byWire. Afterwards, they had the possibility to discuss reasons for and against the usage of Conduct-byWire and were asked to define scenarios, where they could image to use a similar system. Again, almost exactly half of the people were not willing to use the system whereas the other half found numbers of potential usage scenarios. In a first analysis of the results a construct like "affinity towards technology" [12] seemed appropriate to explain the differences between both groups. Surprisingly, in both focus groups one scenario was found in which each participant was willing to use Conduct-by-Wire. This Scenario was the daily commuting to work with a lot of traffic and oneself being tired. Because "affinity towards technology" can be seen as a trait which - per definition - is not subject to changes, another explanation had to be found. This lead to the assumption that the acceptance of our concept is a function of the specific driving situation, because the accepted situation was one, in which all participants stated to have no fun at all.

\subsection{Semi-structured interviews}

To test if the acceptance of our systems (or technical products in general) depends on a certain situation, a series of semi-structured interviews was carried out. Overall, 11 people participated in the interviews. Every interview consisted of 4 isolated parts and lasted between 15 and 45 minutes, depending on the number of considered interview parts. Part one was concerned with general interaction with technical products. The first question was "Are there any technical products you enjoy using? If so, which?" The interview proceeded with the questions "What is enjoyable in the usage of this certain product?" Those questions were asked, because in first place we thought that the enjoyment was in itself due to a design characteristic of the product. With the last question ("At any time is there a point, where you enjoy the usage of this product more or less than normally? When?") the situational dependency was included into the general part of the interview.

Part two (driving a car), part three (playing video games) and part four (driving a motorcycle) were concerned with the pleasure individuals derive from using a certain technology. The technologies were chosen due to the fact that a great number of people experience the execution of those activities as pleasurable or fun [6], [4]. Therefore, only participants with driving license for cars (part two) and/or motorcycles (part four) were asked about the specific technology. The same applies for part three: Only people who play video games were interviewed about video games. Again, aim of the specific parts was to identify pleasurable aspects, and to see if there are changes in the entertainment value over time. A last aspect was the question, if participants would accept a high degree of automation.

Once again, most participants had problems with a high degree of automation in cars and no one was willing to accept automation in video games or while driving a motorcycle, even though it was stated that they should imagine the same safety and that the automation would never act against their will. The interview was semi-structured and enabled the technique of laddering [10]. With the help of this technique all participants ended with their argumentation at a point where they mentioned pleasure when feel- 
ing control over a technical product or system and that automation would reduce this pleasure significantly. Almost all participants felt that pleasure, but it is not expectable that all persons do, because the participants were all members of the department mechanical engineering and therefore do more likely enjoy the interaction with technical products. This led to the idea of "Pleasure of Control" as a personal trait.

\subsection{Pleasure of control as personal trait}

A questionnaire was developed, which integrates all mentioned aspects of pleasure while controlling a technical product. This included pleasure derived from the control over a technical product, the need to take control over technical products as often as possible and as detailed as possible, if these products enable good control and finally, the unwillingness to use highly automated systems. Table 1 shows all questions in English (translationed) and in the original German version.

Table 1

Questions used to measure Pleasure of Control in English translation and German

\begin{tabular}{|c|c|c|}
\hline Number & English & German \\
\hline 1 & $\begin{array}{l}\text { I enjoy having control } \\
\text { over technical sys- } \\
\text { tems }\end{array}$ & $\begin{array}{l}\text { Es macht mir Spaß } \\
\text { Kontrolle über technische } \\
\text { Systeme auszuüben. }\end{array}$ \\
\hline 2 & $\begin{array}{l}\text { I do not like it, if } \\
\text { someone takes con- } \\
\text { trols of technical } \\
\text { systems on my be- } \\
\text { half. }\end{array}$ & $\begin{array}{l}\text { Ich mag es nicht } \\
\text { wenn jemand für mich } \\
\text { die Bedienung von tech- } \\
\text { nischen Systemen über- } \\
\text { nimmt. }\end{array}$ \\
\hline 3 & $\begin{array}{l}\text { Even if I have a } \\
\text { strong control over a } \\
\text { technical system, I } \\
\text { often wish an even } \\
\text { more direct control. }\end{array}$ & $\begin{array}{l}\text { Auch wenn ich ein tech- } \\
\text { nisches System gut be- } \\
\text { herrsche, wünsche ich } \\
\text { mir oftmals eine noch } \\
\text { direktere Kontrolle. }\end{array}$ \\
\hline 4 & $\begin{array}{l}\text { The usage of a tech- } \\
\text { nical system is even } \\
\text { more fun, when I can } \\
\text { realize my aims in } \\
\text { more detail. }\end{array}$ & $\begin{array}{l}\text { Die Benutzung eines } \\
\text { technisches Systems } \\
\text { macht mir umso mehr } \\
\text { Spaß, umso detaillierter } \\
\text { ich die Umsetzung mei- } \\
\text { ner Ziele in Angriff neh- } \\
\text { men kann. }\end{array}$ \\
\hline 5 & $\begin{array}{l}\text { I do not care about } \\
\text { the intermediate steps } \\
\text { during the usage of a } \\
\text { technical system. I } \\
\text { am only interested in } \\
\text { the final result. }\end{array}$ & $\begin{array}{l}\text { Die Zwischenschritte } \\
\text { bei der Benutzung eines } \\
\text { technischen Systems sind } \\
\text { mir egal. Ich möchte nur } \\
\text { ein Endergebnis erzielen. }\end{array}$ \\
\hline 6 & $\begin{array}{l}\text { If I could, I would } \\
\text { stop all automated } \\
\text { actions of a system } \\
\text { and carry them out } \\
\text { myself. }\end{array}$ & $\begin{array}{l}\text { Wenn ich könnte } \\
\text { würde ich alle automati- } \\
\text { schen Handlungen von } \\
\text { technischen Systemen } \\
\text { abschalten und sie selbs }\end{array}$ \\
\hline
\end{tabular}

\begin{tabular}{lll}
\hline & & durchführen. \\
\hline 7 & $\begin{array}{l}\text { To see that I am able } \\
\text { to handle a technical } \\
\text { system gives me a } \\
\text { good feeling. }\end{array}$ & $\begin{array}{l}\text { Zu sehen, dass ich in } \\
\text { der Lage bin ein techni- } \\
\text { sches System zu beherr- } \\
\text { schen gibt mir ein gutes } \\
\text { Gefühl. }\end{array}$ \\
\hline 8 & $\begin{array}{l}\text { I take every chance } \\
\text { to control technical } \\
\text { systems. }\end{array}$ & $\begin{array}{l}\text { Ich nutze alle Gele- } \\
\text { genheiten, um Kontrolle } \\
\text { über technische Systeme } \\
\text { auszuüben. }\end{array}$ \\
\hline
\end{tabular}

With the help of the new construct „Pleasure of Control" (PoC) it could be predicted, that someone with a high PoC enjoys the control over a technical system even more the more detailed he is able to fulfill his task by controlling the interaction. If a system is perceived as easy to control this would lead to a prolonged usage in comparison to users with a low PoC-value. In a last step, the construct could be used as predictor for the willingness to use highly automated systems, which is in general lower for high PoC persons, than for low PoC persons.

\subsection{Differentiation to related constructs}

One problem was to differentiate the construct of pleasure of control from related concepts. In general, control is a famous construct which has a long research tradition in the field of psychology. Some of these areas are concerned with the question if people believe themselves to be able to control the outcome of their actions [11], [15] or if people strive for control [9]. In most cases, control or the belief to be able to control a certain situation is seen as a factor which enables persons to cope with extreme stress (e.g. cancer, exams etc.). Only few concepts (e.g. motif of control) see control as a factor of bringing enjoyment to the individual exercising control.

The herein presented concept Pleasure of Control stresses the positive aspects of control. But it is adopted (and restricted) to the use in the context of technical products. Still, there exists a number of related constructs which are originally developed for usage in the context of technology. The two most important constructs are affinity towards technology [12] and control beliefs in context of technical systems [1]. The concept of affinity towards technology aims for a general attitude towards technical systems. Someone with a high affinity is more likely to use a technical system then someone with a low affinity. Some aspects of the construct "Pleasure of Control" might be associated with affinity towards technology (see table 1 question 8), in terms of number of usages. But the construct affinity towards technology is not 
able to explain why someone is not willing to use highly automated systems or is looking for a more detailed control over a technical system. Instead, a high affinity towards technology would predict enthusiasm for highly automated and very technical systems. Control beliefs in context of technical systems on the other hand, handle the question, if someone beliefs to be able to solve occurring problems with technology on his own. Those control beliefs might moderate if someone uses a certain product or not, but they do not influence, if a user enjoys the control over a system. Therefore, Pleasure of Control is a construct which was developed to predict the usage duration of technical systems in general and to describe an occurring mismatch between expected and observed usage of automated systems.

Imagine a scenario in which you have a passionate old timer driver. With the common constructs "affinity towards technology" and "control beliefs in context of technical systems" you would predict him open to new technologies and able to cope with troubling situations. You would expect therefore, that a system like Conduct-by-Wire would be at least tested by him. In the Conduct-by-Wire studies, users with a similar background and a high affinity towards technology were against our prediction not willing to test our system. The construct of Pleasure of Control is able to explain this mismatch. The focus of such a person would be on the pleasure he derives from the direct interaction and control over the technical system, which is significantly reduced by a high degree of automation. On the other hand, PoC would also explain why he is spending hours on an old timer that is because the systems enables good direct control and therefore is enjoyable for someone with a high Pleasure of control, which leads to prolonged usage. In general, the prolonged usage should be true for all technical systems whereas the low acceptance of automation is only of interest in the context of highly automated systems. The study in the following section concentrates on the aspect of prolonged usage.

\section{Method and results}

\subsection{Method}

To investigate if a high pleasure of control leads to a prolonged system usage, an experimental study was conducted. Overall, 26 participants from 18 to 60 years (mean age 26.96 years) attended the experiment. The sample consisted of 11 female and 15 male participants. All participants were unfamiliar with the Apple iPad 1, which was used as research object in this study.

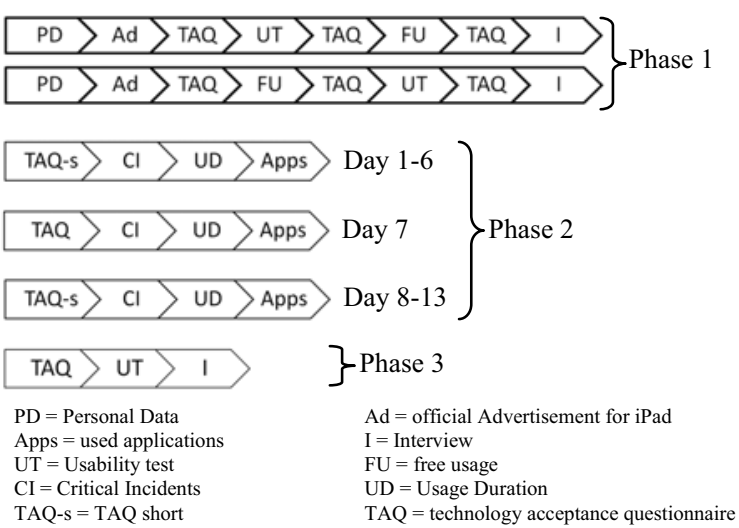

Fig. 1. Test procedure with Phase 1 and 3 being experimental sessions in the lab and Phase 2 being a two week period of home usage. Phase 1 is displayed in both permutations.

Figure 1 shows the test procedure. The experiment consisted of three phases. Phase 1 was a laboratory session in which the participants were introduced to the iPad and took approximately 2.5 hours. First, participants were introduced with the help of the official advertisement, later with a usability test, and a period of free usage. The order of usability test and free usage was permutated. Afterwards in the second phase, participants took the iPad home for a period of two weeks. Within this time they were asked to fill out a diary which included a short version of the technology acceptance questionnaire, a question about critical incidents which shaped their opinion towards the iPad on this day, actual usage durations and the used applications. The experiment ended with a second laboratory test in phase 3 which took 1.5 hours. Main interest of this study was the general acceptance of the iPad but the focus of this work is the investigation of pleasure of control. Therefore, the section results contain only results relevant for the investigation of pleasure of control.

\subsection{Results}

\subsubsection{General results}

First, the reliability of the construct was investigated. Cronbach's alpha was computed to see, if all items belong to the same factor (Pleasure of control). This measure can vary between 0 and 1 where values above .7 are acceptable. The overall alpha for all 8 
items was .585 which is too low. By eliminating the items 4 and 7 Cronbach's alpha was increased to .709.

Because it is easy to assume that Pleasure of Control $(\mathrm{PoC})$ and control beliefs in the context of technology (German abbreviation is KUT) have some similarities the control beliefs were additionally tested with the original items of [1]. A correlation between PoC and KUT (Cronbach's alpha =.855) showed an $\mathrm{R}$ of .198 which is not significant. Therefore, it can be assumed that PoC and KUT are distinct constructs.

Overall, participants used almost the complete scale to rate their Pleasure of Control with a minimum of 2.17 and a maximum of 6.83 . The average PoC was 4.37 with a standard deviation of 0.92 .

\subsubsection{Influence on usage durations}

Within the two weeks of home usage participants were asked to write down their daily usage times. To test if the PoC-value of a person influences the usage durations a comparison of the 5 highest scoring participants with the 5 lowest scoring participants was conducted with the help of a t-test for independent samples. The test showed a significant difference between both groups $(\mathrm{T}=-2,351$; df $=8, \mathrm{p}<.05)$ although the number of participants for each group was really small. Figure 2 shows the average usage durations of both groups during the two weeks of home usage.

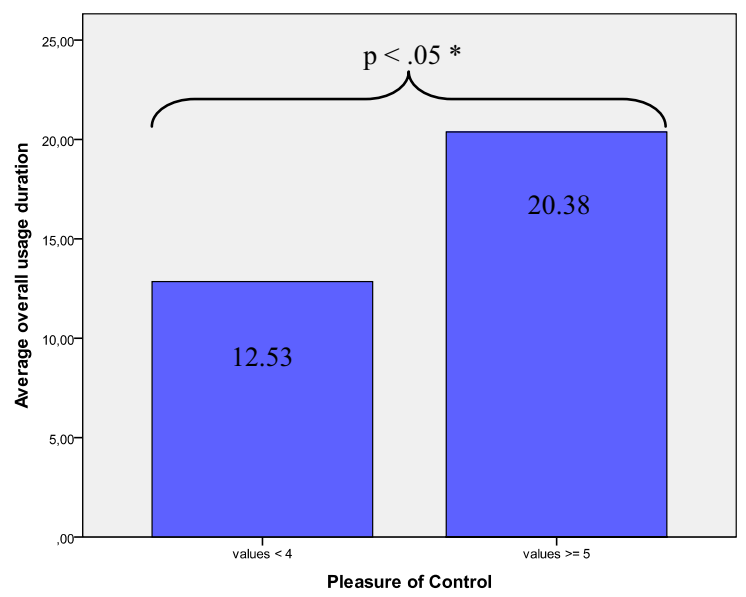

Fig. 2. Average usage durations (h) for lowest/highest PoC-score participants during two weeks home usage.

\section{Discussion}

This paper is a first work dealing with a personal trait called Pleasure of Control. In a first empirical investigation this work was able to show that participants with a high PoC-rating have a longer average usage duration than participants with low PoCratings. Therefore, Pleasure of Control could be an interesting trait for further investigation because it might give a hint to system usage durations. On the other hand, by now Pleasure of Control is a rough idea without deep empirical justification. This becomes very obvious considering the assumption that $\mathrm{PoC}$ is a trait. Although Pleasure of Control is seen as a trait in a first step no data was collected to test the retest reliability of the construct. This implies that no justified statements about the stability of the measure can be made, which is a main criterion for a trait. Further investigations of the construct should take this aspect into account.

Additionally, Pleasure of Control has two main aspects: Prolonged usage of technical systems and unwillingness to accept automated systems. The current study enabled only the evaluation of usage durations because the Apple iPad is not a highly automated system. Therefore, further research should test the construct in the context of highly automated systems to see if the PoC-rating predicts the acceptance of those systems.

Overall, the current study must be seen as a first exploration due to the low number of participants included in the extreme group comparison. Still, there was a significant effect even for this much reduced sample size which indicates a high effect size.

\section{References}

[1] G. Beier, Kontrollüberzeugungen im Umgang mit Technik: Ein Persönlichkeitsmerkmal mit Relevanz für die Gestaltung technischer Systeme. 2004, dissertation.de

[2] F. D. Davis, Perceived usefulness, perceived ease of use, and user acceptance of information technology. MIS Quarterly, 13, 1989, pp. 319-340.

[3] F. D. Davis, R. P. Bagozzi, and P. R. Warshaw, Extrinsic and Intrinsic Motivation to Use Computers in the Workplace. Journal of Applied Social Psychologie, 22, 14, 1992, pp. 1111-1132.

[4] J.P. Gee, Why Video Games are Good For Your Soul: Pleasure and Learning. 2006, Common Ground Publishing Pty ltd.

[5] D. L. Goodhue, and R. L. Thompson, Task technology fit and individual performance. MIS Quarterly, 19, 2, 1995, pp. 213 236. 
[6] J. C. Hallo, and R. E. Manning, Transportation and recreation: a case study of visitors driving for pleasure at Acadia National Park. Journal of Transport Geography 17, 2009, pp. 491-499.

[7] M. Igbaria, S. J. Schiffman, and T. J. Wieckowski, The respective roles of perceived usefulness and perceived fun in the acceptance of microcomputer technology. Behaviour \& Information Technology, 1994, 13, 6, pp. 349-361.

[8] M. Kauer, M. Schreiber, B. Franz, S. Hakuli, S. Geyer, D. Eggers, and R. Bruder, Nutzungsszenarien manöverbasierter Fahrzeugführung. Mensch, Technik, Organisation - Vernetzung im Produktentstehungs- und herstellungsprozess. 57. Kongress der Gesellschaft für Arbeitswissenschaft, 23. -25. März 2011, Chemnitz, pp. 809-812.

[9] A. E. Rijk, P. M. Le Blanc, and W. B. Schaufeli, Active coping and need for control as moderators of the job demandcontrol model: Effects on burnout. Journal of Occupational and Organizational Psychology, 71, 1998, pp. 1-18.

[10]T. J. Reynolds, and J. Gutman, Laddering theory, method, analysis and interpretation, Journal of Advertising Research Feb/March, 1988, pp. 11-31.

[11]J. B. Rotter, Generalized expectations for internal versus external control of reinforcement. Psychological Monographs, $80,1,1966$, whole number 609 .
[12]H. Sacher, S. Hummel, and H. Bubb, Skalenkonstruktion zur Ermittlung der Technikaffinität für die Automobilentwicklung. Tagungsband des 53. Frühjahrskongress der Gesellschaft für Arbeitswissenschaft, 2007, Magdeburg.

[13]B. Suh, and I. Han, Effect of trust on customer acceptance of Internet banking, Electronic Commerce Research and Applications 1, 2002, pp. 247-263.

[14]H. Sun, and P. Zhang, The Role of Moderating factors in user technology acceptance. International Journal of HumanComputer Studies, 64, 2006, pp. $53-78$.

[15] S. E. Taylor, R. R. Lichtman, and J. V. Wood, Attributions, Beliefs About Control, and Adjustment to Breast Cancer. Journal of Personality and Social Psychology, Vol. 46, No. 3, 1984, pp. 489-502

[16] V. Venkatesh, M. G. Morris, G. B. Davis, and F. D. Davis, User acceptance of IT: Toward a unified view. MIS Quarterly, 27, 3, 2003.

[17]H. Winner, and S. Hakuli, Conduct-by-Wire - Following a New Paradigm for Driving into the Future, Proceedings of FISITA World Automotive Congress. 2006.

[18] ISO 9241-110:2006: Ergonomics of human-system interaction -- Part 110: Dialogue principles. 2006, ISO. 